\section{Kidney \\ Blood Pressure \\ Research}

Original Paper

\title{
Association of Age and BP Variability with Long-term Mortality in Hemodialysis Patients
}

\author{
Ha Yeon Kim Yong Un Kang Chang Seong Kim Joon Seok Choi \\ Eun Hui Bae Seong Kwon Ma Soo Wan Kim \\ Department of Internal Medicine, Chonnam National University Medical School, Gwangju, Korea
}

\section{Key Words}

Age $\cdot$ Blood pressure variability $\cdot$ Dialysis

\begin{abstract}
Background/Aims: Blood pressure (BP) variability is known as a poor prognostic factor for cardiovascular outcomes. This study assessed the prognostic significance of BP variability in association with increasing age in hemodialysis patients. Methods: We retrospectively analyzed 2,174 patients on hemodialysis from March 2005 to December 2012. The impact of intradialytic and interdialytic BP variability on all-cause mortality according to age groups was analyzed. Results: Kaplan-Meier survival curves for 5-year cumulative mortality showed higher mortality in patients with higher intradialytic systolic and diastolic BP variability as well as interdialytic systolic and diastolic BP variability (log-rank $p=0.006,<0.001,0.018$ and $<0.001$ ) in patients aged $<55$ years, but not in older age groups. Cox proportional analysis revealed that 5-year mortality was associated with intradialytic diastolic BP variability in patients aged $<55$ years (HR, 2.03 CI, 1.24-3.32). Conclusion: The overall mortality was associated with BP variability in patients aged $<55$ years, but not in older ages. This result suggests that younger hemodialysis patients with BP variability require further medical attention and intervention to reduce $\mathrm{BP}$ variability.
\end{abstract}

Copyright (C) 2014 S. Karger AG, Basel

\section{Introduction}

In patients on maintenance hemodialysis, hypertension is a well-documented risk factor for unfavorable cardiovascular outcomes, such as development of left ventricular hypertrophy, left ventricular dilation, stroke, heart failure, and mortality [1-3]. Clinical practice guidelines focus on recommended BP targets [4]; however, the impact of BP on 


\section{Kidney \\ Blood Pressure Research}

clinical outcomes may vary based on age [5]. An observational cohort study showed that there is a U-shaped association between BP and mortality among patients who are older than 85 years in general population. Very old patients may be at an increased risk from aggressive BP lowering therapy [6]. Together, these findings suggest the clinical impact of high $\mathrm{BP}$ varies with age.

$\mathrm{BP}$ variability and hypertension are proposed to be cardiovascular risk factors. A recent, large retrospective cohort study observed that first-year mortality was higher in hemodialysis patients with variability in BP compared with those with stable BP, independent of absolute BP level, suggesting that BP variability is associated with worse outcomes at all levels of $\mathrm{BP}$ [7]. It has been demonstrated that there is an association between BP variability and end-organ damage and clinical outcomes. Studies in the general population have shown an association between greater BP variability and cardiovascular events [8-11]. Systolic $\mathrm{BP}$ variability is a potent predictor for intima to media wall thickness of the common carotid artery [9] and for increased left ventricular mass [12]. In addition, BP variability has been linked with micro-albuminuria in hypertensive individuals $[13,14]$. Because of the unique BP patterns that occur during hemodialysis, it is difficult to extrapolate these results to hemodialysis patients. Further, most studies focus on patients' average BP level as a prognostic risk factor; however, there has been comparatively little work examining the effects of BP variability in hemodialysis patients at different ages. Herein, we explored the hypothesis that the association between BP variability and all-cause mortality among hemodialysis patients varies at different ages.

\section{Patients and Methods}

\section{Study population}

This study was approved by the institutional review board of Chonnam National University Hospital, Gwangju, Korea (CNUH-2012-108). The institutional review board waived the need for consent given the retrospective design of the project. The mortality data were determined from government death records from Statistics Korea.

We conducted a retrospective evaluation of 2561 patients who had started hemodialysis at Chonnam National University Hospital between March 2005 and December 2012. Of these patients, 387 acute kidney injury patients, who died during hospitalization at the initiation of hemodialysis, were excluded from the study. A total of 2174 patients were included in the analysis.

Demographic, clinical, laboratory, and treatment data were obtained from the hospital's computerized database. We recorded laboratory findings at the initiation of hemodialysis, systolic blood pressure (SBP), diastolic blood pressure (DBP), and pulse pressure. Laboratory measurements included hemoglobin, sodium, albumin, total calcium, inorganic phosphate, and parathyroid hormone (PTH) levels. Other recorded variables included age, gender, and body mass index (BMI). To investigate whether an underlying condition may affect mortality, the presence of pre-existing diabetes, hypertension, and heart failure was identified. The use of therapeutic agents that may alter blood pressure, including angiotensin converting enzyme (ACE) inhibitors or angiotensin receptor blockers (ARB), $\beta$-adrenergic blockers, and calcium channel blockers, was identified.

\section{Definition of blood pressure (BP) variability}

BP data were collected three times at the initiation and completion of each hemodialysis session, and the highest and lowest measurements over the first month of dialysis were identified. Intradialytic BP variability was calculated as the difference between the highest and lowest BP measurements during each dialysis session. Intradialytic SBP variation over $20 \mathrm{~mm} \mathrm{Hg}$ and DBP variation over $10 \mathrm{~mm} \mathrm{Hg}$ were defined as intradialytic SBP and DBP variability, respectively. Interdialytic BP variability was calculated as difference between the BP at the start each dialysis session. Interdialytic SBP variations over $10 \mathrm{~mm} \mathrm{Hg}$ and DBP variation over $5 \mathrm{~mm}$ Hg were defined as interdialytic SBP and DBP variability, respectively. 


\section{Kidney Blood Pressure Research}

Table 1. Baseline characteristics and clinical features of patients divided by age

\begin{tabular}{|c|c|c|c|c|}
\hline & $\begin{array}{c}<55 \text { years } \\
(\mathrm{N}=785)\end{array}$ & $\begin{array}{c}55-74 \text { years } \\
(\mathrm{N}=1099)\end{array}$ & $\begin{array}{c}\geq 75 \text { years } \\
(\mathrm{N}=290)\end{array}$ & P-value \\
\hline Mortality & $105(13.4 \%)$ & $353(32.1 \%)$ & $136(46.9 \%)$ & $<0.001$ \\
\hline Age (years) & $42.7 \pm 9.22$ & $65.0 \pm 5.50$ & $79.1 \pm 3.58$ & $<0.001$ \\
\hline Men (\%) & $477(60.8 \%)$ & $658(59.9 \%)$ & $162(55.6 \%)$ & 0.338 \\
\hline BMI $\left(\mathrm{kg} / \mathrm{m}^{2}\right)$ & $20.7 \pm 12.14$ & $21.3 \pm 6.75$ & $20.6 \pm 7.09$ & 0.056 \\
\hline \multicolumn{5}{|l|}{ Past Medical History } \\
\hline Hypertension & $531(68.8 \%)$ & $884(80.9 \%)$ & $231(79.7 \%)$ & $<0.001$ \\
\hline Diabetes & $298(38.6 \%)$ & $666(60.9 \%)$ & $123(42.4 \%)$ & $<0.001$ \\
\hline Heart failure & $17(2.2 \%)$ & $29(2.7 \%)$ & $18(6.2 \%)$ & 0.002 \\
\hline \multicolumn{5}{|l|}{ Medication } \\
\hline ACE inhibitor or ARB & $239(30.4 \%)$ & 347 (31.5\%) & $109(37.5 \%)$ & 0.210 \\
\hline$\beta$-adrenergic blocker & $331(43.1 \%)$ & $532(48.8 \%)$ & $107(36.9 \%)$ & 0.001 \\
\hline Calcium channel blocker & $478(62.2 \%)$ & 647 (59.4\%) & $145(50.0 \%)$ & 0.001 \\
\hline \multicolumn{5}{|l|}{ Blood Chemistry Profile } \\
\hline Hemoglobin (g/dL) & $9.6 \pm 2.70$ & $9.6 \pm 2.16$ & $9.5 \pm 2.05$ & 0.626 \\
\hline Sodium (mEq/L) & $135.2 \pm 4.99$ & $134.8 \pm 5.43$ & $135.2 \pm 5.40$ & 0.084 \\
\hline Albumin (mg/dL) & $3.4 \pm 1.43$ & $3.2 \pm 0.67$ & $3.2 \pm 0.60$ & 0.228 \\
\hline Total calcium (mg/dL) & $6.8 \pm 2.45$ & $7.4 \pm 3.78$ & $8.0 \pm 1.92$ & $<0.001$ \\
\hline Inorganic-Phosphate $(\mathrm{mg} / \mathrm{dL})$ & $6.1 \pm 6.04$ & $5.0 \pm 2.34$ & $4.8 \pm 1.84$ & 0.044 \\
\hline PTH $(\mathrm{pg} / \mathrm{mL})$ & $245.3 \pm 284.82$ & $189.8 \pm 319.13$ & $129.0 \pm 134.93$ & $<0.001$ \\
\hline SBP (mmHg) & $137.1 \pm 42.35$ & $144.1 \pm 21.32$ & $142.6 \pm 21.86$ & 0.074 \\
\hline $\mathrm{DBP}(\mathrm{mmHg})$ & $82.2 \pm 25.72$ & $80.4 \pm 16.51$ & $75.6 \pm 12.18$ & 0.022 \\
\hline Pulse pressure (mmHg) & $59.1 \pm 22.31$ & $63.5 \pm 17.87$ & $64.2 \pm 16.56$ & 0.001 \\
\hline Intradialytic SBPV (mmHg) & $22.1 \pm 14.02$ & $24.3 \pm 13.73$ & $24.7 \pm 12.52$ & 0.001 \\
\hline Intradialytic DBPV (mmHg) & $13.2 \pm 7.96$ & $13.9 \pm 9.87$ & $14.0 \pm 7.23$ & 0.225 \\
\hline Interdialytic SBPV (mmHg) & $19.2 \pm 10.93$ & $19.8 \pm 10.80$ & $21.5 \pm 10.76$ & 0.011 \\
\hline Interdialytic DBPV (mmHg) & $13.1 \pm 9.92$ & $12.7 \pm 7.76$ & $13.7 \pm 8.42$ & 0.392 \\
\hline \multicolumn{5}{|c|}{$\begin{array}{l}\text { Data are presented as number }(\%) \text { or mean } \pm \text { standard deviation. } \mathrm{BMI}=\text { body mass index; } \mathrm{ACE}= \\
\text { angiotensin-converting enzyme; ARB = angiotensin receptor blocker, } \mathrm{PTH}=\text { parathyroid } \\
\text { hormone; SBP = systolic blood pressure; DBP = diastolic blood pressure; SBPV = systolic blood } \\
\text { pressure variability; DBPV = diastolic blood pressure variability }\end{array}$} \\
\hline
\end{tabular}

\section{Statistical analysis}

Patients were subdivided into three age groups: $<55,55-74$, and $\geq 75$ years. Continuous variables with normal distributions are presented as means \pm standard deviation and were compared using oneway ANOVA. Pearson's chi-squared test was used to evaluate differences between categorical variables. Cox proportional hazards regression analysis was performed to evaluate the prognostic significance of BP variability for mortality in hemodialysis patients. The confounding factors analyzed in this study included age, gender, BMI, comorbidities (hypertension, diabetes, or heart failure), hemoglobin, sodium, albumin, total calcium, and medical treatments at the initiation of hemodialysis. All statistical tests were performed using the Statistical Package for Social Sciences software, version 18.0 (SPSS, an IBM Company, Armonk, NY). P-values $<0.05$ were considered significant.

\section{Results}

\section{Patient Characteristics}

The demographic and clinical features of the patients, divided by age category, are shown in Table 1 . A total of 2174 patients (60.2\% male) were included in the study, with a mean age of $60.0 \pm 14.72$ years. In all, $594(27.3 \%)$ patients died and overall mortality increased with age $(13.4 \%, 32.1 \%$, and $46.9 \%$ for patients aged $<55$ years, $55-74$ years, and $\geq 75$ years, respectively; $\mathrm{P}=0.001$ ). The prevalence of hypertension and diabetes was highest in the 55-74 year group, whereas the prevalence of heart failure, defined as an ejection fraction of less than 40 percent by echocardiogram [15] was highest in the $\geq 75$ years group. 


\section{Kidney \\ Blood Pressure \\ Research}

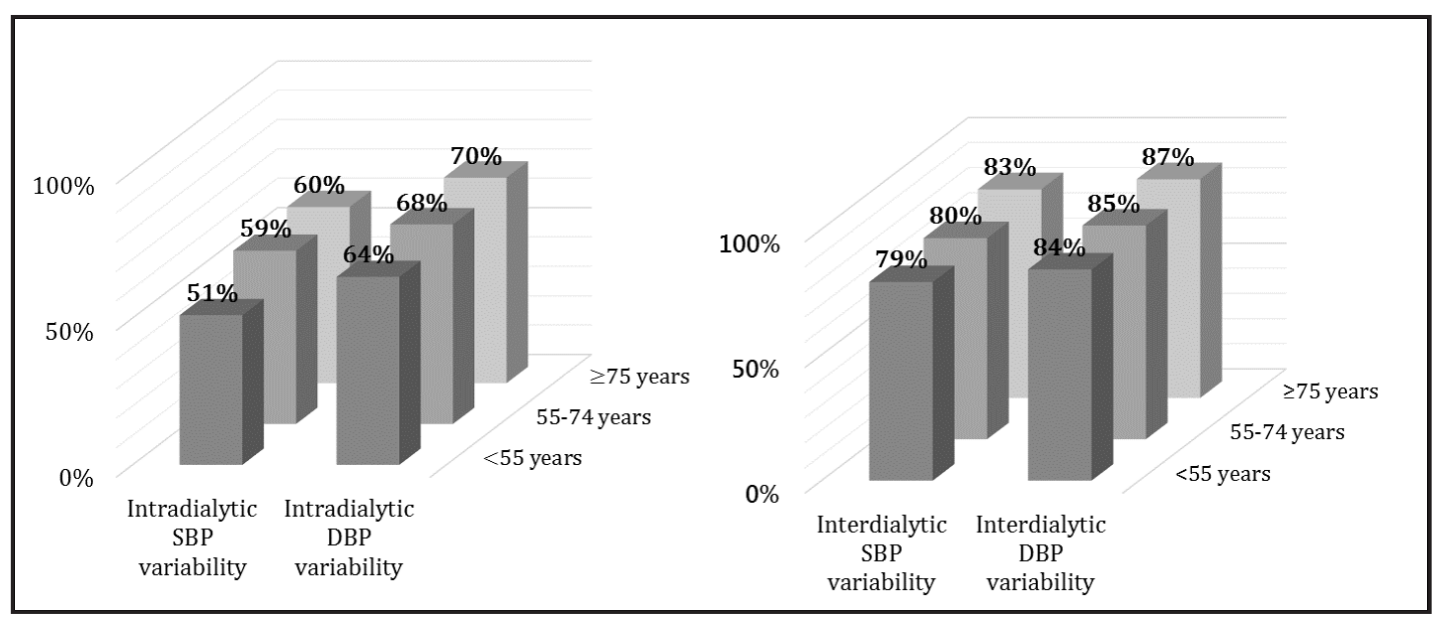

Fig. 1. Prevalence of intradialytic systolic blood pressure (SBP) and diastolic blood pressure (DBP) variability and interdialytic SBP and DBP variability according to age.

$\beta$-Adrenergic blocker use was highest in the 55-74 years group, and calcium channel blocker use was highest in the $<55$ years group. There were no differences in hemoglobin, sodium, and albumin levels between the groups. In contrast, inorganic phosphate levels increased and total calcium decreased with decreasing age. Parathyroid hormone also increased with decreasing age. In the $<55$ years group, the correlation between intradialytic SBP variability $(22.1 \pm 14.02 \mathrm{~mm} \mathrm{Hg})$ and interdialytic SBP variability $(19.2 \pm 10.93 \mathrm{~mm} \mathrm{Hg})$ was significant $(\mathrm{r}=0.107, \mathrm{P}=0.003)$. The correlations between intradialytic SBP variability and intradialytic DBP variability $(13.2 \pm 7.96 \mathrm{~mm} \mathrm{Hg})$ and between interdialytic SBP variability and interdialytic DBP variability $(13.1 \pm 9.92 \mathrm{~mm} \mathrm{Hg})$ were also significant $(\mathrm{r}=0.679, \mathrm{P}<$ 0.001 and $\mathrm{r}=0.489, \mathrm{P}<0.001$; respectively).

Prevalence of $B P$ variability by age category

The prevalence of intradialytic SBP and DBP variability and interdialytic SBP and DBP variability divided by age are shown in Figure 1. As age increased, the prevalence of intradialytic SBP variability increased $(51 \%, 59 \%$, and $60 \%$ for patients aged $<55$ years, $55-74$ years, and $\geq 75$ years, respectively; $\mathrm{P}=0.001$ ). Although the prevalence of intradialytic DBP variability did not differ significantly between the three groups, there was a trend of increasing prevalence of intradialytic DBP variability with increasing age $(64 \%, 68 \%$, and $70 \%$, for patients aged $<55$ years, $55-74$ years, and $\geq 75$ year, respectively; $\mathrm{P}=0.064$ ). The prevalence of interdialytic SBP and DBP variability did not differ significantly between the groups (interdialytic SBP: 79\%, 80\%, and 83\%, for patients aged $<55$ years, $55-74$ years, and $\geq 75$ years, respectively; $\mathrm{P}=0.367$; interdialytic DBP: $84 \%, 85 \%$, and $87 \%$, for patients aged $<55$ years, $55-74$ years, and $\geq 75$ years, respectively; $\mathrm{P}=0.429$ ).

\section{$B P$ variability as a risk factor for 5-year mortality}

We investigated the impact of BP variability on 5-year mortality. Kaplan-Meier survival analysis showed that the survival rate in patients with intradialytic and interdialytic SBP and DBP variability aged $<55$ years was reduced (intradialytic SBP: $\mathrm{P}=0.006$; intradialytic DBP: $\mathrm{P}<0.001$; interdialytic SBP: $\mathrm{P}=0.018$; interdialytic DBP variability: $\mathrm{P}<0.001$; Figures 2 and 3$)$.

To determine if intradialytic and interdialytic SBP and DBP were risk factors for 5-year mortality, Cox proportional analysis was performed (Table 2). In unadjusted Cox proportional analysis, the relative risk for death increased only in patients aged $<55$ years, not in patients aged $55-74$ or in patients aged $\geq 75$ years. In patients aged $<55$ years, intradialytic SBP variability, intradialytic DBP variability, and interdialytic SBP variability were associated 


\section{Kidney \\ Blood Pressure Research}

\section{Kidney Blood Press Res 2013;38:172-180}

DOI: $10.1159 / 000355765$

Published onlıne: Apriा 08, 2014

(C) 2014 S. Karger AG, Basel

www.karger.com/kbr

Kim/Kang/Kim/Choi/Bae/Ma/Kim: Association of Age and BP variability with Mortality

Fig. 2. Kaplan-Meier survival analysis of patients aged $<55$ years divided by intradialytic systolic blood pressure and diastolic blood pressure variability.

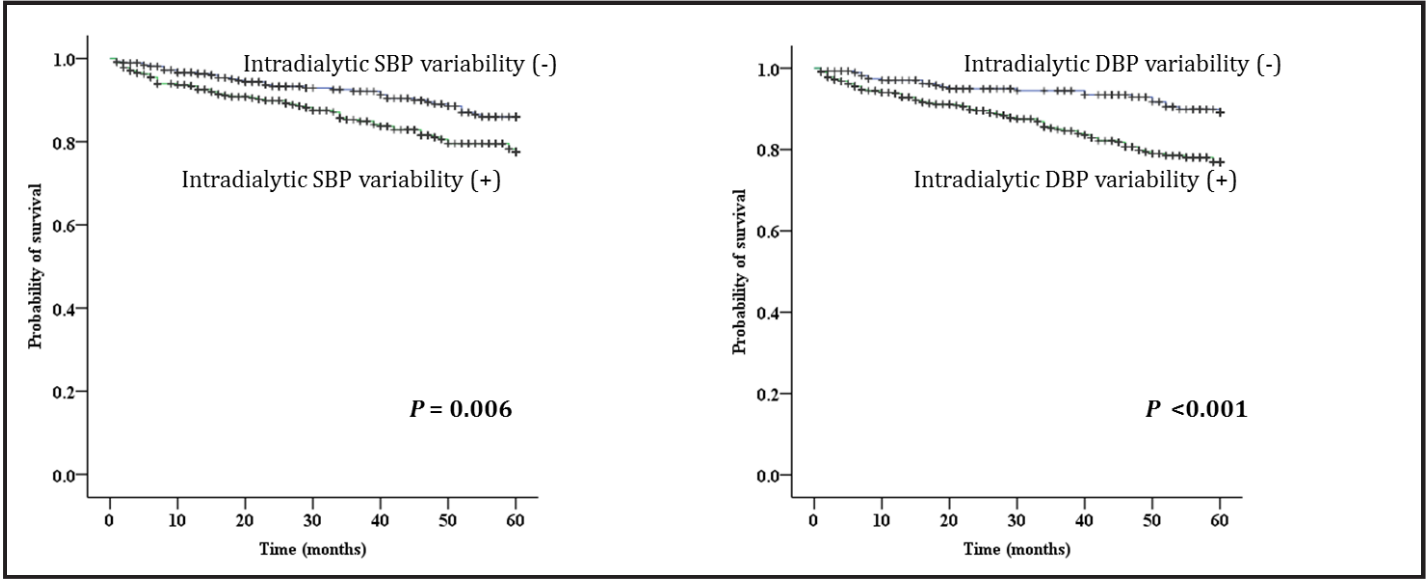

Fig. 3. Kaplan-Meier survival analysis of patients aged $<55$ years divided by interdialytic systolic blood pressure and diastolic blood pressure variability.

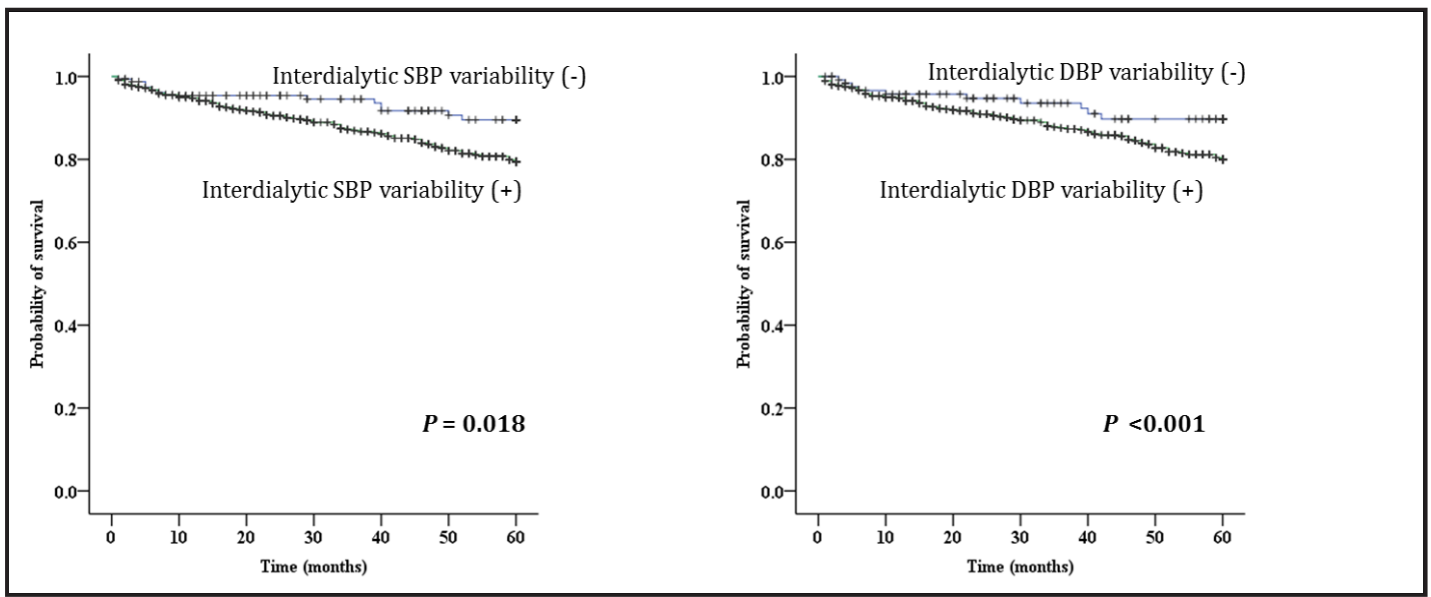

Table 2. Cox proportional analysis for 5-year mortality by blood pressure variability in each age group

\begin{tabular}{|c|c|c|c|c|c|c|}
\hline & \multicolumn{2}{|c|}{$<55$ years } & \multicolumn{2}{|c|}{$55-74$ years } & \multicolumn{2}{|c|}{$\geq 75$ years } \\
\hline & HR $(95 \% \mathrm{CI})$ & P-value & $\operatorname{HR}(95 \% \mathrm{CI})$ & $\mathrm{P}$-value & $\operatorname{HR}(95 \% \mathrm{CI})$ & P-value \\
\hline \multicolumn{7}{|l|}{ Unadjusted model } \\
\hline Intradialytic SBP variability & $1.73(1.16-2.57)$ & 0.007 & $0.96(0.77-1.19)$ & 0.733 & $1.23(0.79-1.59)$ & 0.518 \\
\hline Intradialytic DBP variability & $2.38(1.50-3.79)$ & $<0.001$ & $1.03(0.82-1.30)$ & 0.764 & $0.83(0.57-1.24)$ & 0.333 \\
\hline Interdialytic SBP variability & $1.98(1.11-3.55)$ & 0.021 & $0.85(0.66-1.09)$ & 0.202 & $0.68(0.45-1.04)$ & 0.078 \\
\hline Interdialytic DBP variability & $1.90(0.99-3.65)$ & 0.053 & $0.85(0.64-1.13)$ & 0.284 & $0.63(0.39-1.00)$ & 0.053 \\
\hline \multicolumn{7}{|l|}{ Adjusted model } \\
\hline Intradialytic SBP variability & $1.08(0.70-1.66)$ & 0.714 & $0.90(0.72-1.13)$ & 0.383 & $1.20(0.82-1.75)$ & 0.335 \\
\hline Intradialytic DBP variability & $2.03(1.24-3.32)$ & 0.005 & $1.02(0.81-1.30)$ & 0.828 & $0.79(0.54-1.16)$ & 0.246 \\
\hline Interdialytic SBP variability & $1.67(0.90-3.09)$ & 0.100 & $0.95(0.73-1.23)$ & 0.708 & $0.77(0.49-1.21)$ & 0.272 \\
\hline Interdialytic DBP variability & $1.92(0.96-3.85)$ & 0.064 & $0.93(0.70-1.24)$ & 0.642 & $0.61(0.36-1.01)$ & 0.059 \\
\hline \multicolumn{7}{|c|}{$\begin{array}{l}\text { Adjusted for age (year), gender, comorbid conditions (hypertension, diabetes, and heart failure), medication (ACE inhibitor } \\
\text { or ARB, } \beta \text {-adrenergic blocker, and calcium channel blocker), blood chemistry profile (hemoglobin }(<8 \mathrm{~g} / \mathrm{dL}, 8-12 \mathrm{~g} / \mathrm{dL} \text {, and } \\
>12 \mathrm{~g} / \mathrm{dL}) \text {, Sodium }(<135 \mathrm{mEq} / \mathrm{L} \text { and } \geq 135 \mathrm{mEq} / \mathrm{L}) \text {, Albumin }(<3.5 \mathrm{mg} / \mathrm{dL} \text { and } \geq 3.5 \mathrm{mg} / \mathrm{dL}) \text {, and total calcium }(<8.5 \mathrm{mg} / \mathrm{dL} \text {, } \\
8.5-10.5 \mathrm{mg} / \mathrm{dL} \text {, and }>10.5 \mathrm{mg} / \mathrm{dL})\end{array}$} \\
\hline
\end{tabular}

with 5-year mortality [HR (CI): 1.73 (1.16-2.57), 2.38 (1.50-3.79), and 1.98 (1.11-3.55), respectively]. In adjusted Cox proportional analysis, intradialytic DBP variability was a risk factor of 5-year mortality in patients aged <55 years [HR (CI): 2.03 (1.24-3.32)]. 


\section{Kidney Blood Pressure Research}

In order to determine if additional variables affected 5-year mortality in patients aged $<55$ years, Cox proportional analysis was performed (Table 3). Variables that showed an association of $\mathrm{p}$ $<0.1$ in univariate analysis and/or were clinically plausible were included in this analysis. After adjusting for confounders, 5-year mortality was independently associated with age, diabetes, and hypoalbuminemia (albumin level $<3.5 \mathrm{mg} / \mathrm{dL}$ ).
Kidney Blood Press Res 2013;38:172-180

\begin{tabular}{l|l}
\hline DOI: $10.1159 / 000355765$ & C 2014 S. Karger AG, Basel \\
Published onlIne: ApriI 08, 2014 & www.karger.com/kbr
\end{tabular}

Kim/Kang/Kim/Choi/Bae/Ma/Kim: Association of Age and BP variability with Mortality

Table 3. Cox proportional analysis for 5 -year mortality in patients aged $<55$ years

\begin{tabular}{lcc}
\hline Variables & HR (95\% CI) & P-value \\
\hline Age (year) & $1.06(1.03-1.10)$ & $<0.001$ \\
Gender (female) & $0.70(0.46-1.08)$ & 0.112 \\
Comorbid conditions & & \\
$\quad$ Hypertension & $0.86(0.52-1.43)$ & 0.579 \\
$\quad$ Diabetes & $2.15(1.37-3.36)$ & 0.001 \\
$\quad$ Heart failure & $2.07(0.63-6.75)$ & 0.224 \\
Medication & $1.00(0.61-1.62)$ & 0.998 \\
$\quad$ ACE inhibitor or ARB & $1.15(0.73-1.84)$ & 0.532 \\
$\quad \beta$-adrenergic blocker & $0.96(0.57-1.60)$ & 0.886 \\
$\quad$ Calcium channel blocker & & \\
Blood chemistry profile & $2.22(0.96-5.15)$ & 0.062 \\
$\quad$ Hemoglobin level $<8$ g/dL & $1.51(0.67-3.38)$ & 0.311 \\
$\quad$ Hemoglobin level 8-12 g/dL & $0.99(0.58-1.69)$ & 0.981 \\
$\quad$ Total calcium level < 8.5 mg/dL & $0.30(0.04-2.27)$ & 0.246 \\
$\quad$ Total calcium level $\geq 10.5 \mathrm{mg} / \mathrm{dL}$ & $1.34(0.89-2.03)$ & 0.157 \\
$\quad$ Sodium level <135 mEq/L & $1.58(1.03-2.45)$ & 0.036 \\
$\quad$ Albumin level <3.5 mg/dL & & \\
\hline ACE = angiotensin-converting enzyme; ARB = angiotensin recep- \\
tor blocker
\end{tabular}

\section{Discussion}

Hemodialysis is a stressful hemodynamic procedure that requires adequate cardiovascular compliance. The rapid change in blood volume, electrolyte levels, and osmolality may overwhelm the capacity of the cardiovascular system to respond adequately to stress. During hemodialysis, better cardiovascular compliance is expected in younger patients than in older patients, as younger patients have fewer atherosclerotic diseases and less degenerative changes of their cardiovascular structures. We demonstrated that as age increased, the prevalence of intradialytic SBP variability increased significantly. Similarly, there was a trend of increasing prevalence of intradialytic DBP variability with increasing age. It has been demonstrated by Flythe et al. [16], that intradialytic SBP variability is associated with greater dialytic fluid removal and with demographic characteristics such as older age. It is known that several factors contribute to intradialytic BP variability, including compromised autonomic nervous system and cardiovascular compensatory mechanisms [17]. Elderly patients have a lower tolerance for volume changes, which may be because of the higher morbidity from cardiac dysfunction and impaired vascular compliance. In contrast, we demonstrated that the prevalence of interdialytic BP variability did not differ among the age groups, suggesting that adjustments of cardiovascular compliance in response to acute volume reduction during hemodialysis and interdialytic weight gain vary depending on age.

In elderly hemodialysis patients, the overall clinical status is poor, and renal replacement therapy may further compromise their condition. There is a high prevalence of comorbid conditions, including heart failure and myocardial infarction, which may be associated with poor clinical outcomes [18]. In our study, we found that all-cause mortality increased with increasing age. In addition, the prevalence of heart failure was increased in elderly patients. These findings suggest that age related cardiovascular dysfunctions contribute to poor clinical outcomes in elderly patients. Further, we showed that inorganic phosphate and parathyroid hormone levels increased, while total calcium levels deceased, with decreasing age. These findings are consistent with a previous study that demonstrated that calcium levels were decreased and inorganic phosphate and parathyroid hormone levels were increased in patients aged $<65$ when compared to patients aged $\geq 65$ [19]. These findings 


\section{Kidney Blood Pressure Research}

may be attributed to the lower daily phosphorus intake and the prevalence of a dynamic bone disease in elderly dialysis patients [20].

Increased pulse pressure, which is an indirect measurement of arterial stiffness, is an established risk factor for cardiovascular outcomes and a prognostic factor for mortality in hemodialysis patients [5]. In addition, endothelial dysfunction and arterial stiffness are independently associated with intradialytic hypotension and intradialytic hypertension [21], suggesting that intradialytic BP variability might be associated with distinct vascular changes. In our patients, we demonstrated that pulse pressure increases with age, suggesting that the prevalence of arterial stiffness is higher in older populations and may represent a high risk for BP variability.

It has been suggested that interdialytic BP variability [22] and intradialytic BP variability [23] are associated with increased all-cause and cardiovascular mortality. We demonstrated, using Kaplan-Meier survival curves, that higher mortality is associated with higher intradialytic SBP and DBP variability and higher interdialytic SBP and DBP variability in patients aged $<55$ years but not in the older age groups. The varied prognostic significance of BP variability depending on the age group, along with the high prevalence of BP variability in elderly patients, suggest that mortality risk stratification should not be based on the same BP variability and hemodynamic cut points in the elderly as in younger age groups. Consistent with this, age has been shown to have an impact on the association of mortality with several other common conditions. Higher BP is associated with favorable 5-year survival among subjects aged 75 years and over, whereas the reverse is true for younger patients [24]. Similarly, we have previously demonstrated a differential prognostic significance of renal dysfunction with myocardial infarction [25]. In addition, lower glomerular filtration rate is associated with decreases in mortality with increasing age. The lower relative risk for death attributable to BP variability in older populations may reflect the higher prevalence of comorbidities and other mortality risks, lessening the potential for the single comorbidity of $\mathrm{BP}$ variability to have an impact on mortality.

Using Cox proportional analysis with an adjustment for multiple factors revealed that 5 -year mortality was associated with intradialytic DBP variability only in patients aged $<55$ years. In older patient groups, there was no significant association between 5-year mortality and intradialytic SBP and DBP variability or interdialytic SBP and DBP variability. This suggests that BP variability is a feasible and acceptable variable to use in predicting prognosis in hemodialysis. In addition, the significance of BP variability is more important in younger hemodialysis patients than in older hemodialysis patients.

The present study has several limitations. First, BP was measured at the time of dialysis initiation so the observed BP variability may not be representative of the BP variability present in stable maintenance hemodialysis patients. Second, it was not possible to exclude the possibility of residual confounding factors because of the presence of unmeasured confounders or measurement errors in the included factors. Finally, as this study was a retrospective, single-center, observational study, it was not possible to demonstrate a causal relationship between BP variability and all-cause mortality.

\section{Conclusion}

This study demonstrated that the association between BP variability and all-cause mortality in hemodialysis patients differs by age group. There is an association between 5 -year mortality and BP variability, by Kaplan-Meier survival analysis and Cox proportional hazards regression analysis, only in patients aged $<55$ years. Thus, BP variability has a greater impact on mortality in younger patients. Younger hemodialysis patients with BP variability require further medical attention and intervention to reduce BP variability. 


\section{Kidney \\ Blood Pressure Research}

Kim/Kang/Kim/Choi/Bae/Ma/Kim: Association of Age and BP variability with Mortality

\section{Conflict of Interests}

All the authors have no conflicts of interest to declare.

\section{Acknowledgments}

This research was supported by the Basic Science Research Program through the National Research Foundation of Korea funded by the Ministry of Science, ICT, and Future Planning (2013R1A2A2A01067611) and by the National Research Foundation of Korea grant (MRC for Gene Regulation, 2011-0030132) funded by the Korean government (MSIP).

\section{References}

1 Agarwal R, Nissenson AR, Batlle D, Coyne DW, Trout JR, Warnock DG: Prevalence, treatment, and control of hypertension in chronic hemodialysis patients in the United States. Am J Med 2003;115:291-297.

-2 Mazzuchi N, Carbonell E, Fernandez-Cean J: Importance of blood pressure control in hemodialysis patient survival. Kidney Int 2000;58:2147-2154.

-3 Foley RN, Parfrey PS, Harnett JD, Kent GM, Murray DC, Barre PE: Impact of hypertension on cardiomyopathy, morbidity and mortality in end-stage renal disease. Kidney Int 1996;49:1379-1385.

4 Chobanian AV, Bakris GL, Black HR, Cushman WC, Green LA, Izzo JL Jr, Jones DW, Materson BJ, Oparil S, Wright JT Jr, Roccella EJ; National Heart, Lung, and Blood Institute Joint National Committee on Prevention, Detection, Evaluation, and Treatment of High Blood Pressure; National High Blood Pressure Education Program Coordinating Committee: The Seventh Report of the Joint National Committee on Prevention, Detection, Evaluation, and Treatment of High Blood Pressure: the JNC 7 report. JAMA 2003;289:2560-2572.

5 Klassen PS, Lowrie EG, Reddan DN, DeLong ER, Coladonato JA, Szczech LA, Lazarus JM, Owen WF Jr: Association between pulse pressure and mortality in patients undergoing maintenance hemodialysis. JAMA 2002;287:1548-1555.

-6 Molander L, Lovheim H, Norman T, Nordstrom P, Gustafson Y: Lower systolic blood pressure is associated with greater mortality in people aged 85 and older. J Am Geriatr Soc 2008;56:1853-1859.

7 Raimann JG, Usvyat LA, Thijssen S, Kotanko P, Rogus J, Lacson E Jr, Levin NW: Blood pressure stability in hemodialysis patients confers a survival advantage: results from a large retrospective cohort study. Kidney Int 2012;81:548-558.

8 Kikuya M, Hozawa A, Ohokubo T, Tsuji I, Michimata M, Matsubara M, Ota M, Nagai K, Araki T, Satoh H, Ito S, Hisamichi S, Imai Y: Prognostic significance of blood pressure and heart rate variabilities: the Ohasama study. Hypertension 2000;36:901-906.

-9 Sander D, Klingelhofer J: Diurnal systolic blood pressure variability is the strongest predictor of early carotid atherosclerosis. Neurology 1996;47:500-507.

10 Sander D, Kukla C, Klingelhofer J, Winbeck K, Conrad B: Relationship between circadian blood pressure patterns and progression of early carotid atherosclerosis: A 3-year follow-up study. Circulation 2000;102:1536-1541.

11 Pringle E, Phillips C, Thijs L, Davidson C, Staessen JA, de Leeuw PW, Jaaskivi M, Nachev C, Parati G, O'Brien ET, Tuomilehto J, Webster J, Bulpitt CJ, Fagard RH: Systolic blood pressure variability as a risk factor for stroke and cardiovascular mortality in the elderly hypertensive population. J Hypertens 2003;21:22512157.

12 Verdecchia P, Borgioni C, Ciucci A, Gattobigio R, Schillaci G, Sacchi N, Santucci A, Santucci C, Reboldi G, Porcellati C: Prognostic significance of blood pressure variability in essential hypertension. Blood Press Monit 1996;1:3-11.

13 Tatasciore A, Renda G, Zimarino M, Soccio M, Bilo G, Parati G, Schillaci G, De Caterina R: Awake systolic blood pressure variability correlates with target-organ damage in hypertensive subjects. Hypertension 2007; 50:325-332. 


\section{Kidney \\ Blood Pressure Research}

Kidney Blood Press Res 2013;38:172-180

DOI: $10.1159 / 000355765$

Published online: April 08, 2014

(C) 2014 S. Karger AG, Basel

www.karger.com/kbr

14 Tatasciore A, Zimarino M, Tommasi R, Renda G, Schillaci G, Parati G, De Caterina R: Increased short-term blood pressure variability is associated with early left ventricular systolic dysfunction in newly diagnosed untreated hypertensive patients. J Hypertens 2013;31:1653-1661.

$\checkmark 15$ Yancy CW, Jessup M, Bozkurt B, Butler J, Casey DE Jr, Drazner MH, Fonarow GC, Geraci SA, Horwich T, Januzzi JL, Johnson MR, Kasper EK, Levy WC, Masoudi FA, McBride PE, McMurray JJ, Mitchell JE, Peterson PN, Riegel B, Sam F, Stevenson LW, Tang WH, Tsai EJ, Wilkoff BL; American College of Cardiology Foundation; American Heart Association Task Force on Practice Guidelines: 2013 ACCF/AHA guideline for the management of heart failure: a report of the American College of Cardiology Foundation/American Heart Association Task Force on Practice Guidelines. J Am Coll Cardiol 2013;62:e147-239.

-16 Flythe JE, Kunaparaju S, Dinesh K, Cape K, Feldman HI, Brunelli SM: Factors associated with intradialytic systolic blood pressure variability. Am J Kidney Dis 2012;59:409-418.

17 Desrochers TM, Palma E, Kaplan DL: Tissue-engineered kidney disease models. Adv Drug Deliv Rev DOI: 10.1016/j.addr.2013.12.002.

18 Kurella M, Covinsky KE, Collins AJ, Chertow GM: Octogenarians and nonagenarians starting dialysis in the United States. Ann Intern Med 2007;146:177-183.

19 Kiss I, Kiss Z, Ambrus C, Szabo A, Szegedi J, Balla J, Ladanyi E, Csiky B, Arkossy O, Torok M, Turi S, Kulcsar I: Age-dependent parathormone levels and different CKD-MBD treatment practices of dialysis patients in Hungary--results from a nationwide clinical audit. BMC Nephrol 2013;14:155.

-20 Pelletier S, Roth H, Bouchet JL, Drueke T, London G, Fouque D: Mineral and bone disease pattern in elderly haemodialysis patients. Nephrol Dial Transplant 2010;25:3062-3070.

-21 Dubin R, Owens C, Gasper W, Ganz P, Johansen K: Associations of endothelial dysfunction and arterial stiffness with intradialytic hypotension and hypertension. Hemodial Int 2011;15:350-358.

-22 Chang TI, Flythe JE, Brunelli SM, Muntner P, Greene T, Cheung AK, Chertow GM: Visit-to-visit systolic blood pressure variability and outcomes in hemodialysis. J Hum Hypertens 2014;28:18-24.

-23 Flythe JE, Inrig JK, Shafi T, Chang TI, Cape K, Dinesh K, Kunaparaju S, Brunelli SM: Association of intradialytic blood pressure variability with increased all-cause and cardiovascular mortality in patients treated with long-term hemodialysis. Am J Kidney Dis 2013;61:966-974.

24 Hakala SM, Tilvis RS, Strandberg TE: Blood pressure and mortality in an older population. A 5-year followup of the Helsinki Ageing Study. Eur Heart J 1997;18:1019-1023.

-25 Choi JS, Kim MJ, Kang YU, Kim CS, Bae EH, Ma SK, Ahn YK, Jeong MH, Kim YJ, Cho MC, Kim CJ, Kim SW: Association of age and CKD with prognosis of myocardial infarction. Clin J Am Soc Nephrol 2013;8:939944. 